\title{
Formation of Poly(2-vinylpyridine) Films on Zn by Galvanostatic Electropolymerization
}

\author{
Hiroaki Nakano $^{1}$, Yuki Kuwahara ${ }^{1, *}$, Satoshi Oue ${ }^{1}$, Shigeo Kobayashi ${ }^{2}$, \\ Hisaaki Fukushima ${ }^{1}$ and Jeong-Mo Yoon $^{3}$ \\ ${ }^{1}$ Department of Materials Science \& Engineering, Kyushu University, Fukuoka 812-8581, Japan \\ ${ }^{2}$ Department of Applied Chemistry and Biochemistry, Kyushu Sangyo University, Fukuoka 813-8503, Japan \\ ${ }^{3}$ College of engineering, Chonbuk National University, Chonju, 561-756, Korea
}

\begin{abstract}
Poly(2vinylpyridine) films were deposited on $\mathrm{Zn}$ substrate by electropolymerization using a galvanostatic technique at $30^{\circ} \mathrm{C}$ in $\mathrm{pH} 5$ aqueous solution containing methanol. Films were also formed by employing cyclic voltammetry and potentiostatic techniques; these were compared with those formed using galvanostatic electrolysis. The thickness of films formed by galvanostatic electrolysis increased in proportion to the amount of charge passed during electropolymerization but decreased with increasing current density because of increased hydrogen evolution. The FT-IR spectra and the color of the films suggested that the structure of poly(2-vinylpyridine) films changed from the nonbranched to the branched chain type at higher current densities. The anodic current density for $\mathrm{Zn} \mathrm{dissolution} \mathrm{in} 3 \% \mathrm{NaCl}$ solution was significantly decreased by coating with poly(2-vinylpyridine) films. After electropolymerization at $50 \mathrm{~A} \mathrm{~m}^{-2}$, the anodic reaction was most inhibited, showing excellent corrosion resistance. Although the electrochemical techniques employed had no influence on the thickness or the structure of films, the films formed by galvanostatic electrolysis contained the fewest cracks and gave the best corrosion resistance.
\end{abstract}

(Received October 28, 2004; Accepted December 24, 2004)

Keywords: electropolymerization, 2-vinylpyridine, zinc, galvanostatic electrolysis, cyclic voltammetry

\section{Introduction}

Electrogalvanized steel sheets coated with chromate and thin organic composite films have been extensively used for home electrical appliances as functional conversion-coated steel sheets due to their excellent corrosion resistance and anti-fingerprint capability. ${ }^{1)}$ However, since the hexavalent chromium in chromate films is harmful to the environment, intensive research is being carried out into substitute films for chromate such as organic and molybdate-phosphate..$^{2-4)}$ Electropolymerization of monomers such as aniline, ${ }^{5,6}$ pyrrole $^{7,8)}$ vinyl $^{9-12)}$ and phenol ${ }^{13)}$ is being studied with the aim of forming highly corrosion-resistant film on metal substrates. The properties of polymer films can be controlled by the electrolytic conditions. These polymer films, if uniformly formed on the electrogalvanized steel sheets, have potential for use as substitutes for chromate. It is generally known that the structure and the properties of electropolymerized films vary according to the type of monomer, supporting electrolyte, electrode material, and electrolytic conditions. ${ }^{14)}$

In this study, electroreduction was applied to form the polymer with the aim of not dissolving the $\mathrm{Zn}$ substrate. Monomers of 2-vinylpyridine, which is known to be polymerized by electroreduction, was used. The effect of electrolytic factors on the electropolymerization of 2-vinylpyridine was already reported on Fe substrate. ${ }^{9-11)}$ However, there have been very few studies on $\mathrm{Zn}$ substrate ${ }^{15)}$ whose hydrogen overpotential is significantly different from $\mathrm{Fe}$ substrate. In addition, the effects of electrochemical techniques on the formation of polymers are not recorded. For electropolymerization on electrogalvanized steel sheets in a

*Graduate Student, Kyushu University. Present address: Hinode Suido Co., Ltd., Fukuoka 812-0043, Japan commercial production, the galvanostatic technique is more practical than potentiostatic or cyclic voltammetry techniques. Therefore, in this study, electropolymerization of 2vinylpyridine was tried on $\mathrm{Zn}$ substrate using a galvanostatic technique, and the effect of current density on the structure and the corrosion resistance of poly(2-vinylpyridine) films was investigated. In addition, the poly(2-vinylpyridine) films were produced by cyclic voltammetry and potentiostatic techniques and compared with those produced by galvanostatic electrolysis.

\section{Experimental}

The solution composition and electrolysis conditions for electropolymerization are shown in Table 1 . The electrolytic solution was prepared by dissolving high-grade reagents in solvent. Monomers of 2-vinylpyridine and ammonium perchlorate were used, respectively, as the monomer and supporting electrolyte. The solvent was composed of ionexchanged water and methanol $\left(\mathrm{H}_{2} \mathrm{O}: \mathrm{MeOH}=9: 1\right)$ and the $\mathrm{pH}$ was adjusted to 5 with ammonium perchlorate. Electroreductive polymerization was conducted in un-agitated solution under galvanostatic conditions of $10 \sim 500 \mathrm{~A} \mathrm{~m}^{-2}$ at $30^{\circ} \mathrm{C}$. In some experiments, electropolymerization was also carried out by potentiostatic and cyclic voltammetry techniques to investigate the effects of electrochemical techniques on polymer formation. During electropolymerization, the cathode potentials were measured using a saturated $\mathrm{Ag}$ / $\mathrm{AgCl}$ reference electrode $\left(0.199 \mathrm{~V}\right.$ vs. $\left.\mathrm{NHE}, 25^{\circ} \mathrm{C}\right)$. In the presentation of potential-time curves, the potentials were plotted with reference to NHE. Zinc disks with $10 \mathrm{~mm}$ diameter and platinum sheets, respectively, were used as the cathode and the anode. Each cathode was buffed to mirror smoothness and degreased in acetone solution for $10 \mathrm{~min}$ by ultrasonic cleaning prior to electropolymerization. After 
Table 1 Conditions of electropolymerization.

\begin{tabular}{|c|c|c|c|}
\hline \multicolumn{3}{|c|}{ Item } & Range \\
\hline \multirow{4}{*}{$\begin{array}{l}\text { Bath } \\
\text { composition }\end{array}$} & \multicolumn{2}{|c|}{ 2-vinylpyridine $\left(\mathrm{mol} \cdot \mathrm{dm}^{-3}\right)$} & 0.25 \\
\hline & \multicolumn{2}{|c|}{ Ammonium perchlorate $\left(\mathrm{mol} \cdot \mathrm{dm}^{-3}\right)$} & 0.05 \\
\hline & \multicolumn{2}{|c|}{ Water:Methanol (volume ratio) } & $9: 1$ \\
\hline & \multicolumn{2}{|c|}{$\mathrm{pH}$} & 5.0 \\
\hline \multirow{8}{*}{$\begin{array}{l}\text { Operating } \\
\text { conditions }\end{array}$} & $\begin{array}{l}\text { Galvanostatic } \\
\text { electrolysis }\end{array}$ & $\begin{array}{l}\text { Current density } \\
\left(\mathrm{A} \cdot \mathrm{m}^{-2}\right)\end{array}$ & $\begin{array}{l}10 \sim-500 \\
{[50]}\end{array}$ \\
\hline & \multirow{2}{*}{$\begin{array}{l}\text { Cyclic } \\
\text { voltammetry }\end{array}$} & $\begin{array}{l}\text { Potential range } \\
\text { (V vs. NHE) }\end{array}$ & $-0.9 \sim-1.8$ \\
\hline & & $\begin{array}{l}\text { Sweep rate } \\
\qquad\left(\mathrm{mV} \cdot \mathrm{s}^{-1}\right)\end{array}$ & 20 \\
\hline & $\begin{array}{l}\text { Potentiostatic } \\
\text { electrolysis }\end{array}$ & $\begin{array}{l}\text { Potential } \\
\text { (V vs. NHE) }\end{array}$ & -1.3 \\
\hline & Temperature & & 30 \\
\hline & Cathode & & $\mathrm{Zn}(\phi 10 \mathrm{~mm})$ \\
\hline & Anode & & $\mathrm{Pt}$ \\
\hline & Quiescent bat & & \\
\hline
\end{tabular}

[]: standard condition

electropolymerization, the cathode was immediately washed with distilled and ion-exchanged water and dried in a vacuum chamber for 24 hours. The thickness of films deposited on the cathode was measured using a color laser 3D profile microscope (VK-8500, Keyence Company). The laser beam is reflected at both the film surface and the interface between the film and $\mathrm{Zn}$ substrate. The reflected laser beam is accepted at a detector and the amount of accepted laser beam become maximum at fitted focus point of lens. There are two peaks of amount of accepted laser beam at two particular distances from objective lens because the laser beam is reflected at two points as described above. The difference in the two particular distances from objective lens corresponds to the ratio of the film thickness to the index of refraction of film. The film thickness was calculated using the index of refraction 1.5 of the poly(2-vinylpyridine) films. The morphology and the structure of the films were examined by scanning electron microscopy (SEM) and Fourier transform infrared spectroscopy (FT-IR), respectively. After the zinc disc coated with poly(2-vinylpyridine) films was immersed in $3 \% \mathrm{NaCl}$ solution at $25^{\circ} \mathrm{C}$ for $3 \mathrm{~h}$ in an air atmosphere, the polarization curves were measured by polarizing from rest potential to the cathodic potential direction, and then to the anodic potential direction using the potential sweep method at $20 \mathrm{mV} \mathrm{min}^{-1}$.

\section{Results and Discussion}

\subsection{Effect of current density on polymer formation}

The time-dependence of the cathode potential during galvanostatic and coulostatic electrolysis in the electrolyte containing a monomer of 2-vinylpyridine is shown in Fig. 1. The cathode potentials are almost constant at about $-1.0 \mathrm{~V}$ vs. NHE at low current densities of 10 and $30 \mathrm{~A} \mathrm{~m}^{-2}$, whereas, with $50 \mathrm{~A} \mathrm{~m}^{-2}$ and above, they rapidly shift to more cathodic values after the initial stage of steady potential at $-1.0 \mathrm{~V}$. The cathode potentials change earlier with higher current density. The potential shift to cathodic direction

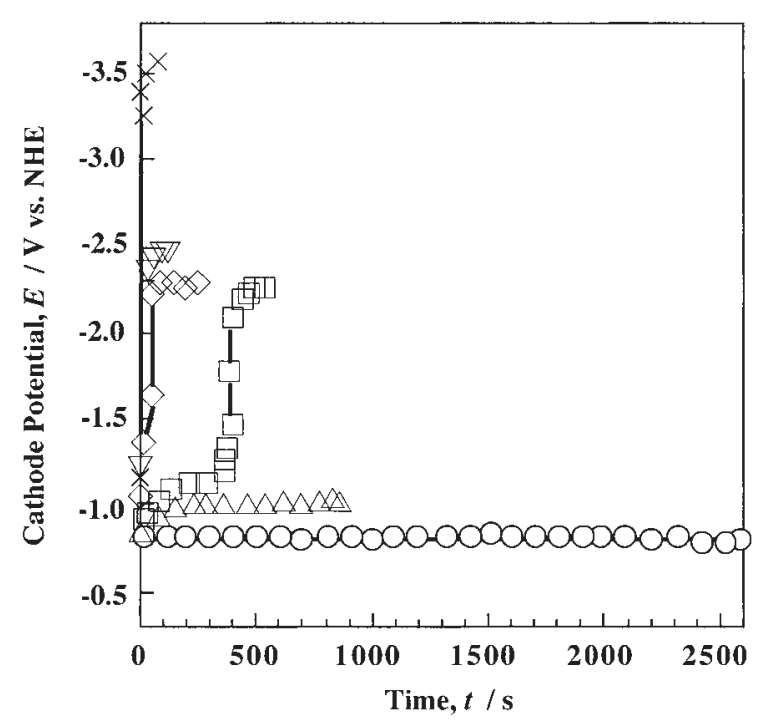

Fig. 1 Effect of current density on the time-dependence of the cathode potential during galvanostatic and coulostatic electropolymerization of 2vinylpyridine. $\left(2.55 \mathrm{C} \cdot \mathrm{cm}^{-2}\right)$ Current density: (O) $10 \mathrm{~A} \cdot \mathrm{m}^{-2},(\triangle)$ $30 \mathrm{~A} \cdot \mathrm{m}^{-2}, \quad(\square) 50 \mathrm{~A} \cdot \mathrm{m}^{-2}, \quad(\diamond) 100 \mathrm{~A} \cdot \mathrm{m}^{-2}, \quad(\nabla) 200 \mathrm{~A} \cdot \mathrm{m}^{-2}, \quad(\times)$ $500 \mathrm{~A} \cdot \mathrm{m}^{-2}$.

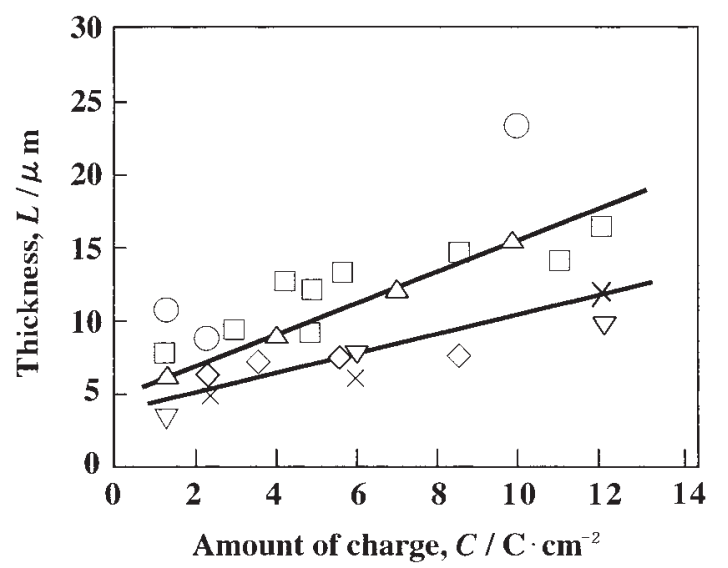

Fig. 2 Relationship between the amount of charge and thickness of films formed at various current densities by galvanostatic electrolysis. Current density: $(\bigcirc) 10 \mathrm{~A} \cdot \mathrm{m}^{-2},(\triangle) 30 \mathrm{~A} \cdot \mathrm{m}^{-2},(\square) 50 \mathrm{~A} \cdot \mathrm{m}^{-2},(\diamond) 100 \mathrm{~A} \cdot \mathrm{m}^{-2}$, ( $) 200 \mathrm{~A} \cdot \mathrm{m}^{-2},(\times) 500 \mathrm{~A} \cdot \mathrm{m}^{-2}$.

appears to be attributed to the increased resistance of the films formed on the cathode by electrolysis.

Figure 2 shows the relationship between the amount of charge passed during electrolysis and the thickness of films formed with various current densities by galvanostatic electrolysis. With every current density, the thickness of the films increases with increased amount of charge. As seen from a comparison of the films formed at the same amount of charge, they are thinner with a high current density of $100 \sim 500 \mathrm{~A} \mathrm{~m}^{-2}$ than at a low current density of $10 \sim$ $50 \mathrm{~A} \mathrm{~m}^{-2}$. This can be explained by assuming that hydrogen evolution occurs simultaneously during the polymerization and that the partial current of hydrogen evolution increases with increased current density. It is recognized that thick films are formed with low current densities of 10 and $30 \mathrm{~A} \mathrm{~m}^{-2}$, at which the cathode potential is only slightly 


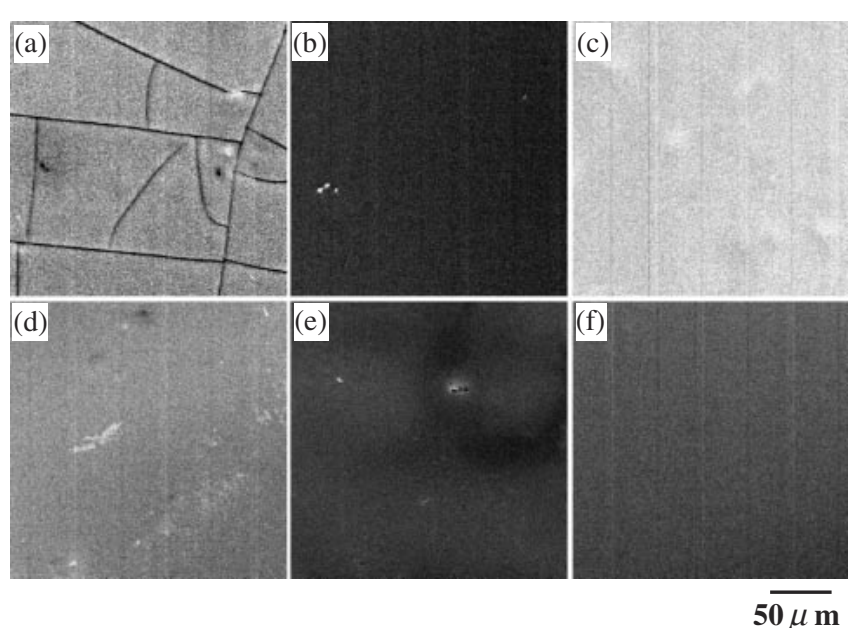

Fig. 3 Effect of current density on the morphology of films obtained by galvanostatic and coulostatic electrolysis. $\left(2.55 \mathrm{C} \cdot \mathrm{cm}^{-2}\right)$. Current density: (a) $10 \mathrm{~A} \cdot \mathrm{m}^{-2}$, (b) $30 \mathrm{~A} \cdot \mathrm{m}^{-2}$, (c) $50 \mathrm{~A} \cdot \mathrm{m}^{-2}$, (d) $100 \mathrm{~A} \cdot \mathrm{m}^{-2}$, (e) $200 \mathrm{~A} \cdot \mathrm{m}^{-2}$, (f) $500 \mathrm{~A} \cdot \mathrm{m}^{-2}$.

polarized at about $-1.0 \mathrm{~V}$. Figure 2 reveals that the shift of potential in the cathodic direction during galvanostatic polymerization, as shown in Fig. 1, is not caused only by the increase in film thickness.

Figure 3 shows the morphology of films obtained with various current densities by galvanostatic and coulostatic $\left(2.55 \mathrm{C} \mathrm{cm}^{-2}\right)$ electrolysis in the solution containing 2vinylpyridine monomer. Small cracks are observed all over the films produced with $10 \mathrm{~A} \mathrm{~m}^{-2}$, whereas with $30 \mathrm{~A} \mathrm{~m}^{-2}$ and above, the films show a smooth surface with no cracks. The film with $10 \mathrm{~A} \mathrm{~m}^{-2}$ was colorless and transparent, but the films with current densities exceeding $10 \mathrm{~A} \mathrm{~m}^{-2}$ were yellow. The intensity of yellowish tone increased with increasing current density.

The morphology of the films obtained at various amounts of charge by galvanostatic electrolysis with $50 \mathrm{~A} \mathrm{~m}^{-2}$ is shown in Fig. 4. The white areas and dark areas in Fig. 4(a) respectively represent the zinc substrate and poly(2-vinyl-
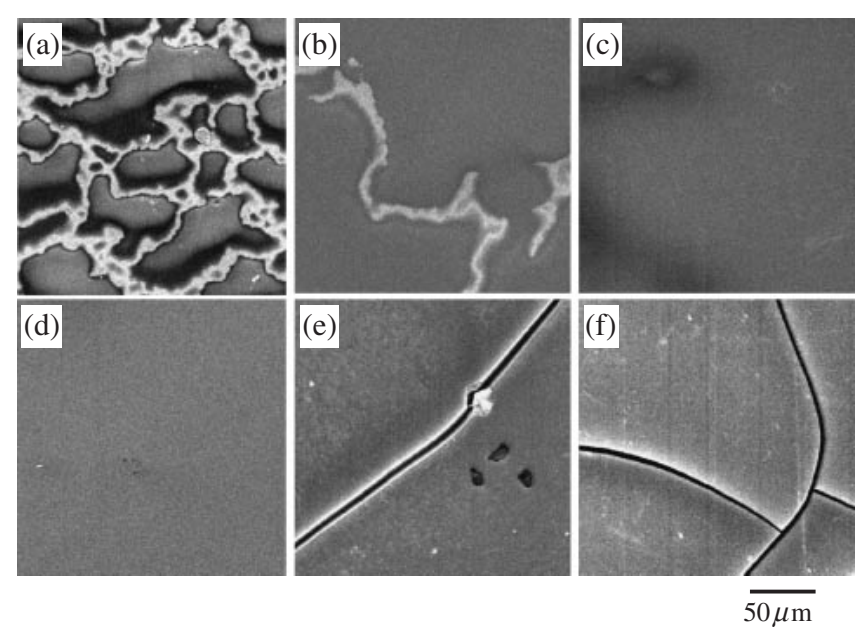

Fig. 4 Morphology of the films obtained at $50 \mathrm{~A} \cdot \mathrm{m}^{-2}$ by galvanostatic electrolysis of various amounts of charge. Amount of charge: (a) $0.3 \mathrm{C} \cdot \mathrm{cm}^{-2}$, (b) $0.5 \mathrm{C} \cdot \mathrm{cm}^{-2}$, (c) $1.5 \mathrm{C} \cdot \mathrm{cm}^{-2}$, (d) $3 \mathrm{C} \cdot \mathrm{cm}^{-2}$, (e) $7.5 \mathrm{C} \cdot \mathrm{cm}^{-2}$, (f) $9 \mathrm{C} \cdot \mathrm{cm}^{-2}$. pyridine) film. At a low amount of charge $\left(0.3 \mathrm{C} \mathrm{cm}^{-2}\right)$, the poly(2-vinylpyridine) film consists of islands about $50 \mu \mathrm{m}$ in diameter. The substrate is exposed between the islands. The island-like film grows two-dimensionally with increased amount of charge and, at $1.5 \mathrm{C} \mathrm{cm}^{-2}$ and above, completely coats the substrate (Figs. 4(c)-(d)). As the amount of charge is further increased, cracks occur in the film due to increased film thickness (Figs. 4(e)-(f)). Observation of the films obtained at various amounts of charge and current densities revealed that cracks in the film readily occurred with decreased the current density. Figure 1 shows that the cathode potential after electropolymerization with $50 \mathrm{~A} \mathrm{~m}^{-2}$ significantly shifted in the cathodic direction at $2 \mathrm{C} \mathrm{cm}^{-2}$ (400 s). However, this amount of charge $\left(2 \mathrm{C} \mathrm{cm}^{-2}\right)$ is not in agreement with the amount of charge to completely coat the substrate with the films, indicating that a remarkable potential shift to cathodic direction during electropolymerization does not occur when the films eventually completely coat the substrate.

\subsection{Effect of current density on the structure of electro- polymerized films}

The structure of the films formed by galvanostatic electrolysis in the solution containing the monomer of 2-vinylpyridine was investigated by FT-IR. The effect of current density on the structure of the films is shown in Fig. 5. All of the films obtained with various current densities show absorption peaks at the wavenumbers characteristic of the stretching vibration of $\mathrm{C}-\mathrm{H}, \mathrm{C}-\mathrm{C}$ and $\mathrm{C}-\mathrm{N}$ bonds, indicating that the poly(2-vinylpyridine) film was clearly produced by galvanostatic electrolysis. The intensity and the wavenumber of absorption peaks for stretching vibration of $\mathrm{C}-\mathrm{H}, \mathrm{C}-\mathrm{C}$ and $\mathrm{C}-\mathrm{N}$ bonds are almost constant, regardless of current density.

Figure 6 shows the FT-IR spectra at low wavenumbers for poly(2-vinylpyridine) films. Although the films produced with 200 and $500 \mathrm{~A} \mathrm{~m}^{-2}$ show absorption peaks around $1100 \mathrm{~cm}^{-1}$, the wavenumber of these absorption peaks shifts to the direction of higher value with decreased current density, reaching $1130 \mathrm{~cm}^{-1}$ at $10 \mathrm{~A} \mathrm{~m}^{-2}$. The absorption peak for vibration of the pyridine ring was reported to be present around $1100 \mathrm{~cm}^{-1}{ }^{16)}$ It has also been observed that the color of poly(2-vinylpyridine) films changes to yellow when the structure of the films changes from the nonbranched to the branched chain type. ${ }^{17)}$ In this study, the poly(2-vinylpyridine) films changed from colorless and transparent to yellow on increasing the current density, suggesting that the structure of the films changed from the non-branched to the branched chain type as shown in Fig. 7 with an increase in current density. Consequently, the shift of absorption peaks around the wavenumber of $1100 \mathrm{~cm}^{-1}$ should be caused by the change of the structure of the poly(2-vinylpyridine) films as shown in Fig. 7. The cathode potentials shift rapidly to lower values during galvanostatic electropolymerization with increasing the current density, as shown in Fig. 1. The remarkable shift of the cathode potential during electrolysis could be partially attributed to the change in the film structure from the non-branched chain to the branched chain type. 


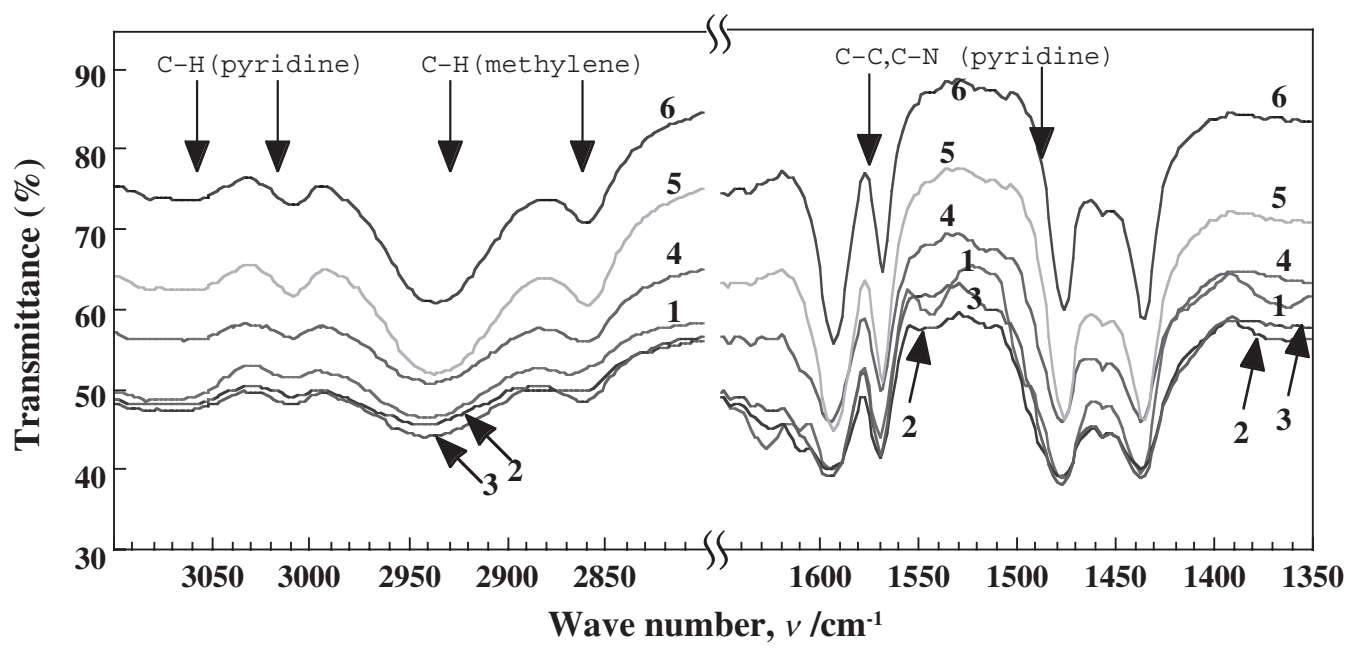

Fig. 5 FT-IR spectra of the films obtained at various current densities by galvanostatic electrolysis. $\left(2.55 \mathrm{C} \cdot \mathrm{cm}^{-2}\right) \mathrm{Current}$ density: (1) $10 \mathrm{~A} \cdot \mathrm{m}^{-2}$, (2) $30 \mathrm{~A} \cdot \mathrm{m}^{-2}$, (3) $50 \mathrm{~A} \cdot \mathrm{m}^{-2}$, (4) $100 \mathrm{~A} \cdot \mathrm{m}^{-2}$, (5) $200 \mathrm{~A} \cdot \mathrm{m}^{-2}$, (6) $500 \mathrm{~A} \cdot \mathrm{m}^{-2}$.

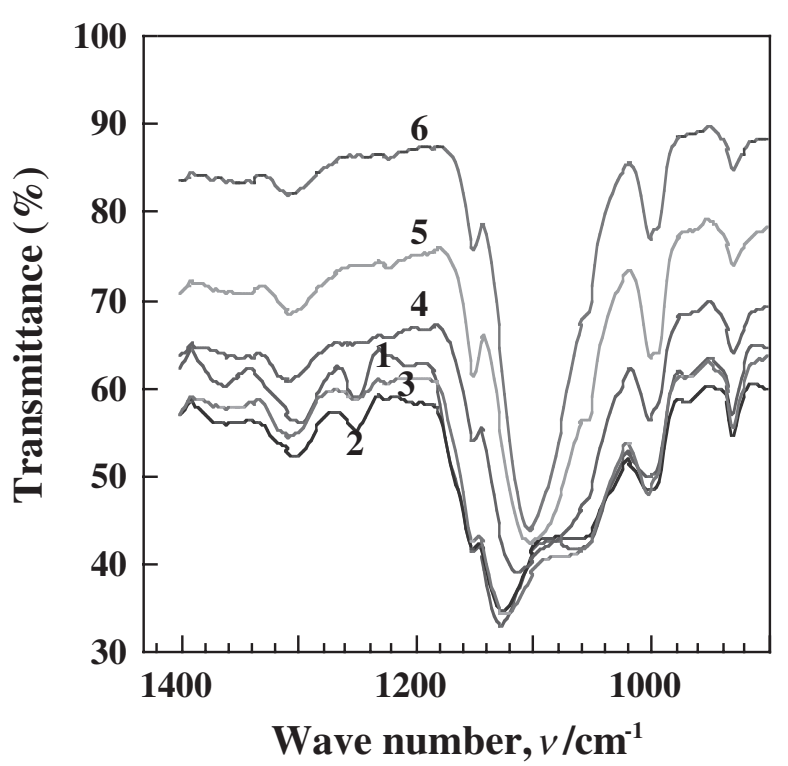

Fig. 6 FT-IR spectra of the poly(2-vinylpyridine) films obtained at various current densities by galvanostatic electrolysis. $\left(2.55 \mathrm{C} \cdot \mathrm{cm}^{-2}\right)$ Current density: (1) $10 \mathrm{~A} \cdot \mathrm{m}^{-2}$, (2) $30 \mathrm{~A} \cdot \mathrm{m}^{-2}$, (3) $50 \mathrm{~A} \cdot \mathrm{m}^{-2}$, (4) $100 \mathrm{~A} \cdot \mathrm{m}^{-2}$, (5) $200 \mathrm{~A} \cdot \mathrm{m}^{-2}$, (6) $500 \mathrm{~A} \cdot \mathrm{m}^{-2}$.

\subsection{Effect of current density on the corrosion resistance of electropolymerized film}

The corrosion resistance of $\mathrm{Zn}$ coated with the poly(2-vinylpyridine) films was evaluated by measuring polarization curves. The poly(2-vinylpyridine) film was formed by galvanostatic and coulostatic $\left(12.7 \mathrm{C} \mathrm{cm}^{-2}\right)$ electrolysis. Figure 8 shows the polarization curves of $\mathrm{Zn}$ coated with poly(2-vinylpyridine) films and poly(2-vinylpyridine) filmfree $\mathrm{Zn}$. The anodic and the cathodic reactions, respectively, in this study are expressed in the following eqs. (1) and (2).

$$
\begin{aligned}
& \mathrm{Zn} \rightarrow \mathrm{Zn}^{2+}+2 \mathrm{e}^{-} \\
& 1 / 2 \mathrm{O}_{2}+\mathrm{H}_{2} \mathrm{O}+2 \mathrm{e}^{-} \rightarrow 2 \mathrm{OH}^{-}
\end{aligned}
$$

As can be seen in Fig. 8, both the anodic and the cathodic current densities decrease by the coating of poly(2-vinyl- (a)<smiles>CCC(CCC(CCC(CCC(CC)c1ccccn1)c1ccccn1)c1ccccn1)c1ccccn1</smiles>

(b)

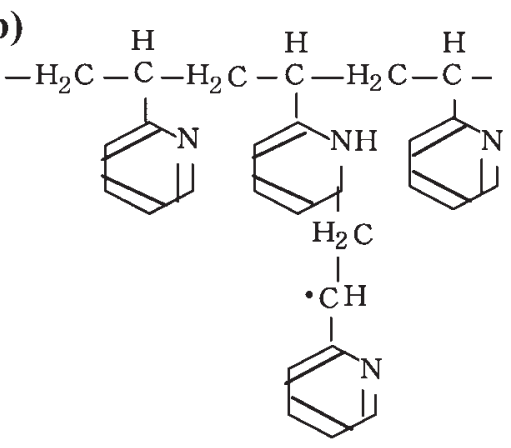

Fig. 7 Structure of the poly(2-vinylpyridine) films. (a) Non-branched chain type (b) Branched chain type.

pyridine) films, indicating that poly(2-vinylpyridine) films formed on $\mathrm{Zn}$ act as inhibitors of both anodic and cathodic reactions. The anodic current density shown in Fig. 8 is evidently dependent on the current density of electropolymerization. The anodic reaction (1) is inhibited most greatly after electropolymerization with $50 \mathrm{~A} \mathrm{~m}^{-2}$, which means that the corrosion resistance of $\mathrm{Zn}$ peaks with electropolymerization with $50 \mathrm{~A} \mathrm{~m}^{-2}$. With a high current density of $500 \mathrm{~A} \mathrm{~m}^{-2}$ and low current density of $10 \mathrm{~A} \mathrm{~m}^{-2}$ of electropolymerization, the anodic current densities are higher than after electropolymerization at $50 \mathrm{~A} \mathrm{~m}^{-2}$. Increase in the current density of electropolymerization leads to thinner poly(2-vinylpyridine) films, as shown in Fig. 2, because of an increase in the partial current of hydrogen evolution, resulting in a higher anodic current density. On the other hand, when decreasing the current density of electropolymerization, cracks readily occurs in the films, as shown in 


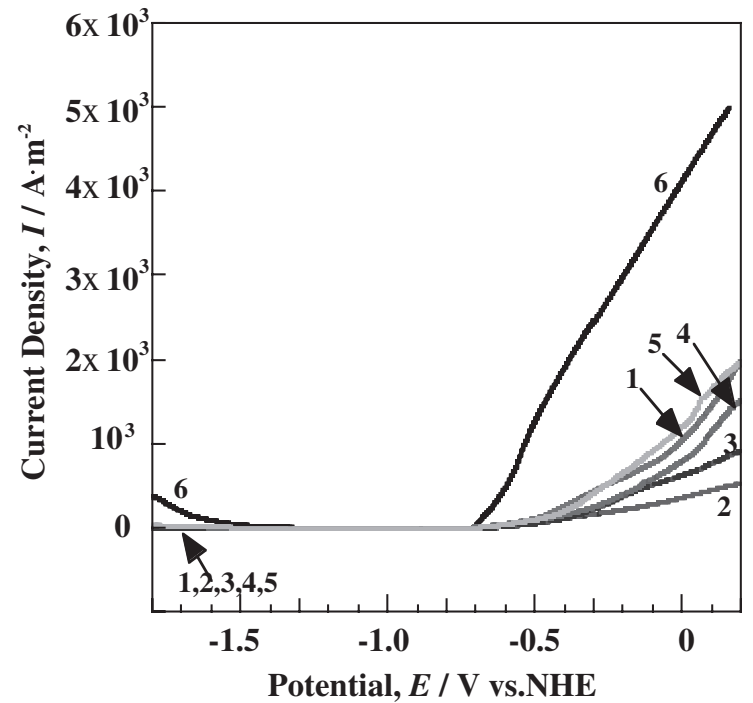

Fig. 8 Polarization curves of $\mathrm{Zn}$ coated with poly(2-vinylpyridine) formed at various current densities. $\left(12.7 \mathrm{C} \cdot \mathrm{cm}^{-2}\right)$ Current density: (1) $10 \mathrm{~A} \cdot \mathrm{m}^{-2}$, (2) $50 \mathrm{~A} \cdot \mathrm{m}^{-2}$, (3) $100 \mathrm{~A} \cdot \mathrm{m}^{-2}$, (4) $200 \mathrm{~A} \cdot \mathrm{m}^{-2}$, (5) $500 \mathrm{~A} \cdot \mathrm{m}^{-2}$, (6) poly(2-vinylpyridine)-free $\mathrm{Zn}$.

Fig. 3, and the structure of the films changes to the nonbranched chain type, resulting in a small improvement in the corrosion resistance of $\mathrm{Zn}$. As related above, it was found that there was an optimum electropolymerization current density from the viewpoint of corrosion resistance. However, even with electropolymerization at $50 \mathrm{~A} \mathrm{~m}^{-2}$, the anodic current density of about $350 \mathrm{~A} \mathrm{~m}^{-2}$ was observed at $0 \mathrm{~V}$. This can be explained by dissolution of $\mathrm{Zn}$ through imperfections in the poly(2-vinylpyridine) films. Therefore, it is expected that the anodic current density is further decreased if the film is more perfectly formed.

\subsection{Effect of electrochemical technique on the formation of poly(2-vinylpyridine) films}

So far in this study, we have discussed only the poly(2-vinylpyridine) films formed by galvanostatic electrolysis. We also produced poly(2-vinylpyridine) films by potentiostatic and cyclic voltammetry techniques and compared them with those produced by galvanostatic electrolysis. Potentiostatic and the cyclic voltammetry electrolysis was conducted under conditions leading to the poly(2-vinylpyridine) films being uniformly and smoothly laid down. The thickness of the films formed by potentiostatic and cyclic voltammetry techniques was also measured by a color laser 3D profile microscope. No influence was observed of electrochemical technique on film thickness. Figure 9 shows the morphology of the poly(2-vinylpyridine) films obtained by various electrochemical techniques. At a low amount of charge $\left(1.3 \mathrm{C} \mathrm{cm}^{-2}\right)$, the poly(2-vinylpyridine) film appears as smooth films with no cracks, regardless of electrochemical technique, while increase in the amount of charge to $2.6 \mathrm{C} \mathrm{cm}^{-2}$ in potentiostatic electrolysis leads to the film containing numerous and widely-distributed cracks. Further increasing the amount of charge to $4.5 \mathrm{C} \mathrm{cm}^{-2}$, although the film obtained by cyclic voltammetry technique also contained cracks, the film formed by galvanostatic electrolysis
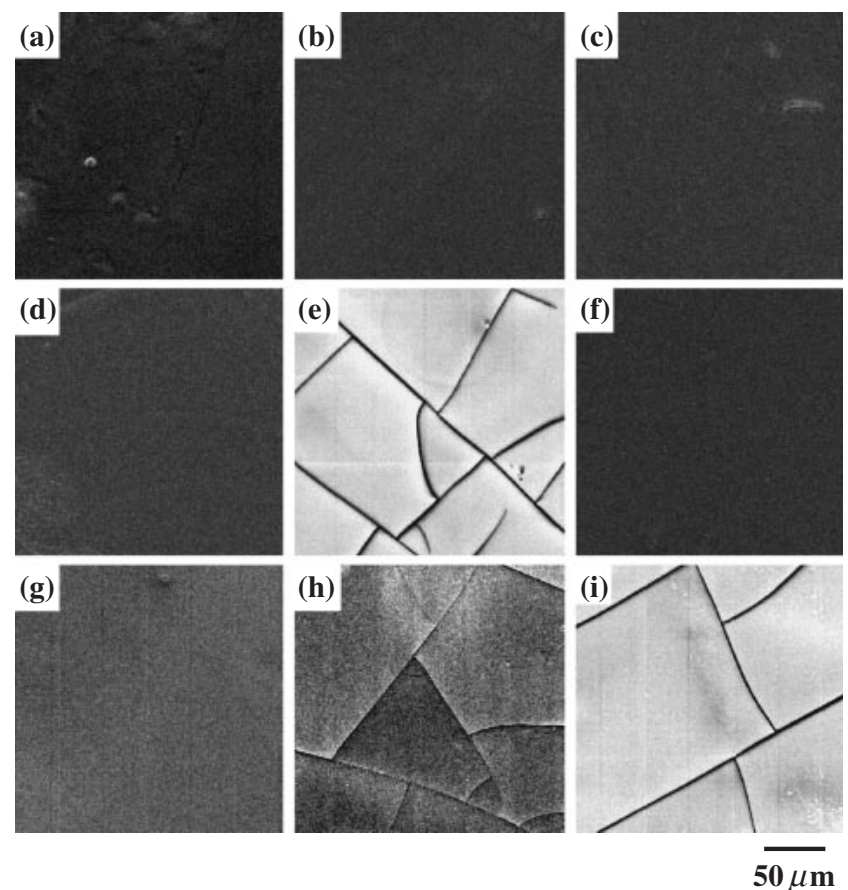

\begin{tabular}{l|c|c|c}
\hline & Galvanostatic & Potentiostatic & Voltammetry \\
\hline $1.3 \mathrm{C} \cdot \mathrm{cm}^{-2}$ & (a) & (b) & (c) \\
\hline $2.6 \mathrm{C} \cdot \mathrm{cm}^{-2}$ & (d) & (e) & (f) \\
\hline $4.5 \mathrm{C} \cdot \mathrm{cm}^{-2}$ & (g) & (h) & (i) \\
\hline
\end{tabular}

Fig. 9 Effect of electrochemical technique on the morphology of poly(2-vinylpyridine) films.

contained none. It has been reported that the poly(2-vinylpyridine) films formed by cyclic voltammetry are more uniform than those produced by other electrochemical techniques. ${ }^{10)}$ However, in this study, galvanostatic electrolysis produced the most uniform films with the fewest cracks. The fewer cracks seen with galvanostatic electrolysis can be explained by assuming that the electropolymerization current concentrates on the cracks, filling in any areas where cracks occur during electrolysis. On the other hand, in potentiostatic electrolysis, the current density was high at the initial stage but decreased as electropolymerization proceeded; consequently, the cracks were not ultimately filled in.

Figure 10 shows the FT-IR spectra of poly(2-vinylpyridine) films obtained by various electrochemical techniques.

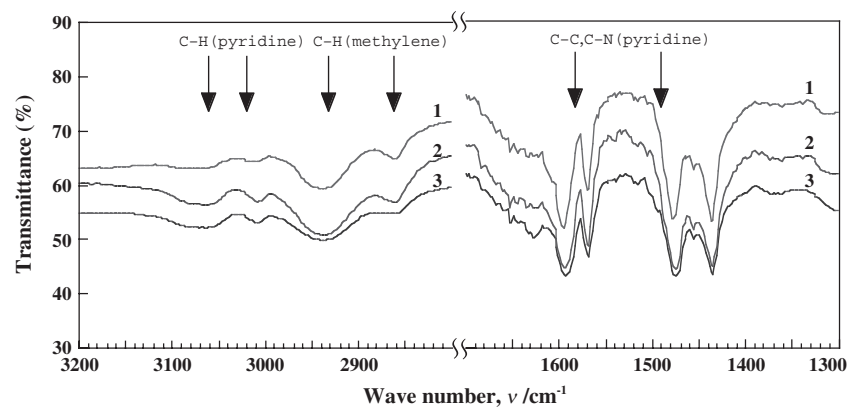

Fig. 10 FT-IR spectra of the poly(2-vinylpyridine) films obtained at various electrochemical techniques. $\left(1.3 \mathrm{C} \cdot \mathrm{cm}^{-2}\right)$ (1) Galvanostatic electrolysis, (2) Potentiostatic electrolysis, (3) Cyclic voltammetry. 


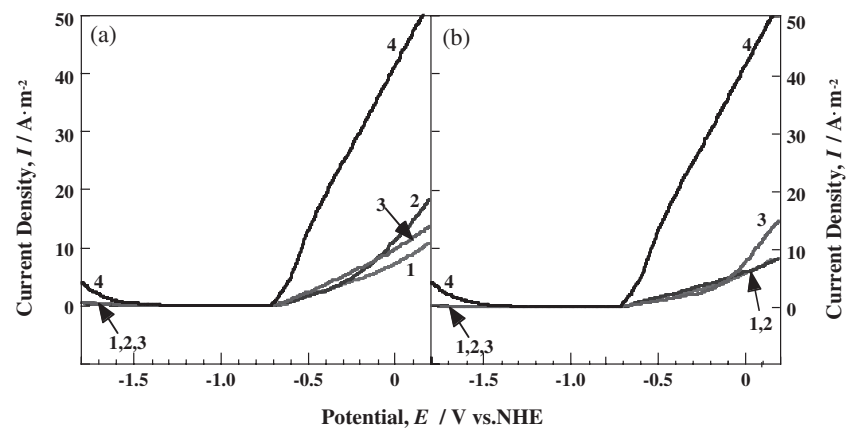

Fig. 11 Polarization curves of $\mathrm{Zn}$ coated with poly(2-vinylpyridine) formed at amount of charge of $1.3 \mathrm{C} \cdot \mathrm{cm}^{-2}$ (a) and $4.5 \mathrm{C} \cdot \mathrm{cm}^{-2}$ (b) by various electrochemical techniques. (1) Galvanostatic electrolysis, (2) Potentiostatic electrolysis, (3) Cyclic voltammetry, (4) poly(2-vinylpyridine)-free $\mathrm{Zn}$.

All the films show absorption peaks at the wavenumbers for stretching vibration of $\mathrm{C}-\mathrm{H}, \mathrm{C}-\mathrm{C}$ and $\mathrm{C}-\mathrm{N}$ bonds of poly(2-vinylpyridine). There were no differences in the intensity or the wavenumber of their absorption peaks among the electrochemical techniques. All the films were uniformly yellow. The results above suggest that the structure of a poly(2-vinylpyridine) film does not depend on the electrochemical technique used to form it.

Figure 11 shows the polarization curves of $\mathrm{Zn}$ with poly(2-vinylpyridine) films formed by various electrochemical techniques and the poly(2-vinylpyridine) film-free Zn. All the anodic current densities significantly decrease by coating poly(2-vinylpyridine) films on $\mathrm{Zn}$, suggesting that all the films are markedly effective in inhibiting the dissolution of $\mathrm{Zn}$. As seen from a comparison of the films formed at a low amount of charge $\left(1.3 \mathrm{C} \mathrm{cm}^{-2}\right)$, the anodic current density was slightly lower with galvanostatic electrolysis than with other electrochemical techniques (Fig. 11(a)). However, increase in the amount of charge to $4.5 \mathrm{C} \mathrm{cm}^{-2}$ leads to convergence of anodic current density for each electrochemical technique (Fig. 11(b)). These results suggest that the films produced by galvanostatic electrolysis are most efficiently corrosion-resistant in the case of thin films, but the influence of the electrochemical technique disappears as film thickness increases. Although the films formed at $4.5 \mathrm{C} \mathrm{cm}^{-2}$ by cyclic voltammetry and potentiostatic techniques contain cracks, their resistance to corrosion is identical to that of crack-free films formed by galvanostatic electrolysis. In the case of thin films, the corrosion resistance depends on the presence of cracks, but the effects of cracks decrease with increased film thickness. Based on the discussions presented above, it can be concluded that the galvanostatic technique is suitable for the formation of poly(2-vinylpyridine) films on electrogalvanized steel sheets in commercial production lines.

\section{Conclusion}

The formation of poly(2-vinylpyridine) films by galvanostatic electrolysis was attempted on $\mathrm{Zn}$ and the effect of current density on the structure and the corrosion resistance of the films was investigated. The poly(2-vinylpyridine) films were also produced by cyclic voltammetry and potentiostatic techniques and were compared with those formed by galvanostatic electrolysis. The thickness of films formed by galvanostatic electrolysis increased linearly with the amount of charge but decreased with increasing current density due to increased hydrogen evolution. Based on FT-IR spectra and the color of the films, it was presumed that the structure of poly(2-vinylpyridine) films changed from the non-branched type to the branched chain type at higher current densities. The anodic current density for $\mathrm{Zn}$ dissolution in $3 \% \mathrm{NaCl}$ solution significantly decreased by coating with poly(2-vinylpyridine) films. After electropolymerization at $50 \mathrm{~A} \mathrm{~m}^{-2}$, the anodic reaction was almost entirely inhibited, resulting in excellent corrosion resistance. Although the electrochemical techniques employed had no effect on the thickness or structure of the films, the films formed by galvanostatic electrolysis contained the fewest cracks and showed the best corrosion resistance.

\section{REFERENCES}

1) H. Sakai, K. Miki, T. Nakamoto, M. Nakamura and K. Miyamoto: Kobe Steel Eng. Rep. 40 (1990) 93-97.

2) T. Aoe: J. Surf. Finish. Soc. Jpn. 49 (1998) 221-229.

3) M. Uetani: J. Surf. Finish. Soc. Jpn. Memorial supplement 51 (2000) 84-91.

4) P. T. Tang, G. Bech-Nielsen and P. Meller: Transactions of the Institute of Metal Finishing 75 (1997) 144-149.

5) E. W. Paul, A. J. Ricco and M. S. Wrighton: J. Phys. Chem. 89 (1985) 1441-1446.

6) S. H. Glarum and J. H. Marshall: J. Electrochem. Soc. 134 (1987) 2160-2166.

7) M. Schirmeisen and F. Beck: J. Appl. Electrochem. 19 (1989) 401-407.

8) C. A. Ferreira, S. Aeiyach, M. Delamar and P. C. Lacaze: J. Electroanal. Chem. 284 (1990) 351-357.

9) X. Ling, J. J. Byerley, M. D. Pritzker and C. M. Burns: J. Appl. Electrochem. 27 (1997) 1343-1348.

10) X. Ling, M. D. Pritzker, C. M. Burns and J. J. Byerley: J. Appl. Electrochem. 29 (1999) 1005-1013.

11) M. Yuasa, T. Sugiyama and I. Sekine: J. Surf. Finish. Soc. Jpn. 44 (1993) 230-236.

12) S. P. Lee, H. Nakano, S. Oue, T. Akiyama, H. Fukushima and J. M. Yoon: Tetsu-to-Hagane 88 (2002) 513-519.

13) N. Oyama, T. Ohsaka, T. Hirokawa and T. Suzuki: J. Chem. Soc., Chem. Commun. (1987) 1133-11139.

14) K. Naoi and Y. Oura: J. Surf. Finish. Soc. Jpn. 46 (1995) 1110-1114.

15) A. D. Bruyne, J. L. Delplancke and R. Winand: J. Appl. Electrochem. 25 (1995) 284-290.

16) H. Horiguchi: Sekigaikyukozusetsusoran, (in Japanese, Sankyosyuppan, Tokyo, 1973) pp 93.

17) X. Ling, M. D. Pritzker, C. M. Burns and J. J. Byerley: Macromolecules. 31 (1998) 9134-9140. 